\title{
Extreme rainfall and drinking water quality: a regional perspective
}

\author{
A. Grinham ${ }^{1}$, B. Gibbes ${ }^{1}$, D. Gale ${ }^{2}$, A. Watkinson ${ }^{2} \&$ M. Bartkow ${ }^{2}$ \\ ${ }^{1}$ School of Civil Engineering, The University of Queensland, Australia \\ ${ }^{2}$ Seqwater, Brisbane, Australia
}

\begin{abstract}
Record high, extreme rainfall intensities were observed in South East Queensland, Australia in January 2011, resulting in drinking water storages above capacity and subsequent floods. This paper focuses on changes, and subsequent recovery, in water quality due to sediment and nutrient loading associated with these high inflows across the region's water supplies. In total, 8 systems were routinely monitored and results indicate that storages with larger and more degraded catchment areas experienced greater declines in water quality relative to storages with smaller, less disturbed catchments. A case study focussing on Wivenhoe Dam, the primary water supply for the region, revealed large scale sediment inputs to the system, estimated to between 1.5 and 20 million tonnes. These were accompanied by high nutrient and metal loads, and water column turbidity above water quality guidelines persisted for a period of at least 6 months after inflows. Given the increased likelihood of such intense inflow events in the future, sound catchment management appears imperative to reduce negative impacts on storage water quality.
\end{abstract}

Keywords: extreme flooding, SEQ, sediment loading, turbidity, water storage.

\section{Introduction}

The austral summer 2010/2011 season in Queensland, Australia was characterised by an extreme La Nina event with record rainfall across the state. December 2010 was the wettest month on record with $70 \%$ of the state declared a disaster zone [1]. A 5 day period from 6th to 11th January 2011 saw extreme rainfall recorded in South East Queensland with rainfall intensities exceeding 100 year annual recurrence level and total decile rainfall ranked well above 
average or highest on record [2]. Widespread flooding occurred in South East Queensland with the cities of Brisbane and Ipswich experiencing the highest flood level since 1974 and recovery costs estimated to be approximately AU\$10 billion [3]. The 1974 flood was triggered by a decaying cyclone system whilst the 2011 flood was due to a persistent coastal low producing widespread rainfall for an extended period of time [4].

The region's drinking water supplies experienced large to extreme inflows with all storages recording over $100 \%$ capacity during this period [5]. Accompanying these inflows were associated sediment and pollutant loadings, potentially negatively impacting on the storage's water quality. Increased turbidity or total suspended solids (TSS) concentrations may be seen directly after large scale inflow events, where determining particle size of suspended solids aid in estimating settling times and the persistence of such turbid conditions. It is further useful to determine the organic fraction of suspended solids as well as the nitrogen, phosphorus, sulphur, iron and manganese concentrations, as these are likely to modify sediment biogeochemical cycling upon settling. In addition, long term changes may include the reduction of metals, where subsequent diffusion into the water column can lead to taste and odour issues in the treatment process [6] as well as remineralisation of nitrogen and phosphorus that leads to increased likelihood of algal blooms [6]. Such algal blooms are likely to increase water treatment time and costs, especially if toxic algal species are involved. Extreme rainfall events are projected to increase within the next decade [7] and there is therefore an urgent need to better understand the impact of extreme inflows on the water quality of South East Queensland's water storages.

\section{Materials and methods}

\subsection{Study site description}

South East Queensland is located in the sub-tropics (Fig. 1A) and is characterized by wet, hot summers and dry, mild winters [8]. The region is home to over 3 million people [9] and has undergone significant catchment modification with less than $20 \%$ of the catchment now classified as pristine [10]. A total of 8 water storages from northern, central and southern parts of South East Queensland (Fig. 1B) were monitored in this study, and forms part of a regional monitoring programme. These storages vary widely in capacity, catchment area and catchment land use practice (Table 1). The storages located in the central region (North Pine Dam - NPD, Somerset Dam - SOM and Wivenhoe Dam - WIV) generally have larger catchments and storage capacity as well as relatively high catchment modification (Table 1). The storages located in northern (Cooloolabin Dam - COO and Baroon Pocket Dam - BPD) and southern (Leslie Harrison Dam - LHD, Hinze Dam - HIN and Little Nerang Dam - LND) regions are generally smaller in catchment area and storage capacity and have lower catchment modification (Table 1). 


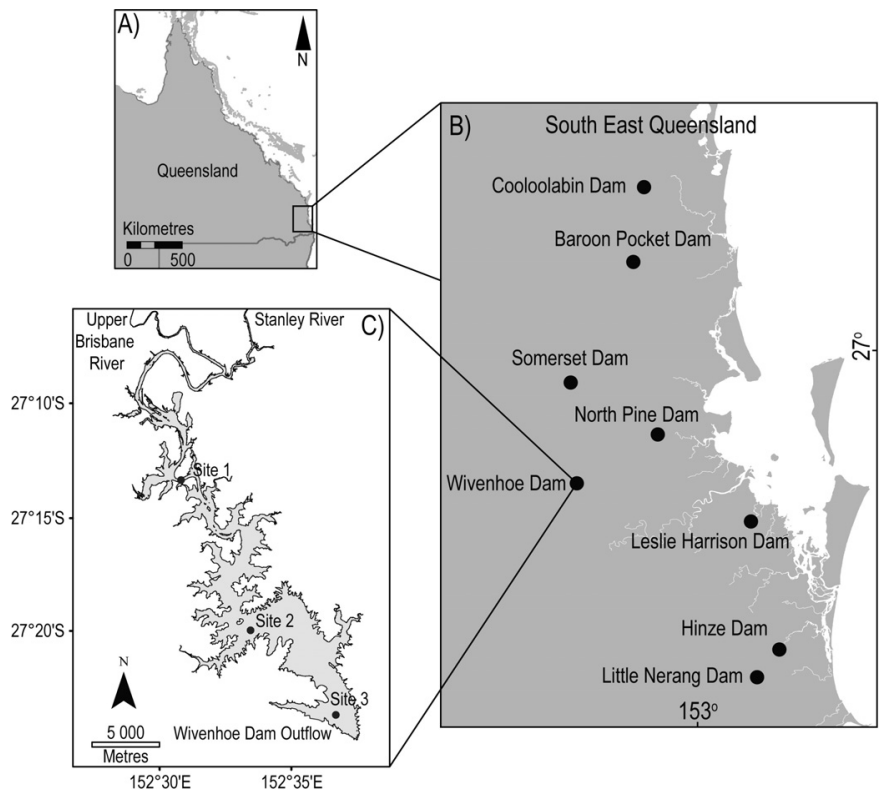

Figure 1: A) Study region relative to Queensland and Australia, B) sampling storages in the present study and C) sampling sites within Wivenhoe Dam.

Overall, the catchments for all the storages retain reasonable natural vegetation cover with half or more classified in this category for all storages (Table 1).

Table 1: $\quad$ Water storage characteristics (in order of catchment size).

\begin{tabular}{|c|c|c|c|c|c|}
\hline \multirow{2}{*}{ Water storage } & \multirow{2}{*}{$\begin{array}{l}\text { Catchment } \\
\text { area }\left(\mathrm{km}^{2}\right)\end{array}$} & \multirow{2}{*}{$\begin{array}{c}\text { Capacity } \\
\text { (ML) }\end{array}$} & \multicolumn{3}{|c|}{ Catchment land use (\%) } \\
\hline & & & Natural & Grazing & Other \\
\hline Cooloolabin Dam & 8 & 13800 & 72 & 6 & 22 \\
\hline Little Nerang Dam & 35 & 6705 & 80 & 14 & 6 \\
\hline Baroon Pocket Dam & 72 & 61000 & 49 & 42 & 9 \\
\hline Leslie Harrison Dam & 87 & 24868 & 60 & 15 & 25 \\
\hline Hinze Dam & 207 & 310730 & 80 & 14 & 6 \\
\hline North Pine Dam & 348 & 211958 & 62 & 29 & 9 \\
\hline Somerset Dam & 1340 & 379849 & 55 & 42 & 3 \\
\hline Wivenhoe Dam & 7020 & 1165238 & 49 & 47 & 4 \\
\hline
\end{tabular}

\subsection{Regional water storage sampling}

Discrete water samples for total suspended solids (TSS) analysis were collected from surface waters and $1 \mathrm{~m}$ above the sediment surface using a Niskin bottle at standard monitoring sites within each storage. These monitoring sites vary in number from 3 sites in smaller storages to 9 sites in larger storages. Sites within each storage are located to capture riverine, transition and lacustrine zones. 
Hinze Dam, Wivenhoe Dam and North Pine Dam were sampled on $19^{\text {th }}-21^{\text {st }}$ January 2011, one week after the major inflow event. Monthly sampling then commenced on all 8 water storages in mid February 2011 and continued monthly for selected storages (WIV, NPD and HIN) until no further decline in TSS concentration was observed. TSS concentration was estimated from filtering a known volume of sample water through a pre-weighed GFF (nominal pore size $0.7 \mu \mathrm{m})$ and drying to constant weight at $110^{\circ} \mathrm{C}$. Inorganic suspended solids were determined by combusting the dried samples at $550^{\circ} \mathrm{C}$ for $2 \mathrm{~h}$ [11].

\subsection{Wivenhoe Dam case study}

Wivenhoe Dam is the region's primary water storage and the largest both in capacity and catchment area (Table 1). The Upper Brisbane River drains directly into the storage, whilst the Stanley River inflow is just downstream of the Somerset Dam and therefore can be viewed as an outflow point from Somerset Dam. Two gauging stations are located on the Upper Brisbane River immediately prior to entering the storage, these are located at Gregor's Creek and Cressbrook Creek. Both have rising stage samplers to collect discrete TSS samples at selected stages over inflow events. Particle size analysis used a laser diffraction method (Malvern Mastersizer 2000, Malvern Instruments Ltd, UK) with samples sonicated for 1 minute prior to measurement to break apart aggregates of particles, allowing the true particle size to be calculated [12]. Turbidity profiles (YSI 6951 vertical profiler, YSI Inc., Florida) were collected every $3 \mathrm{~h}$ from permanent profilers adjacent the dam wall of both Somerset Dam and Wivenhoe Dam prior to, during, and after the inflows. To estimate sediment nutrient and metal loading accompanying inflows, three replicate sediment cores were collected from each site using a gravity corer fitted with acrylic liners (Fig. 1C). Sampling occurred in April 2011 when turbidity profiles indicated much of the particle settling had occurred (see Fig. 4). Cores were extruded in field and the top $2 \mathrm{~cm}$ transferred to zip lock bags and stored frozen $\left(-20^{\circ} \mathrm{C}\right)$ until analysis. Nutrient and metal analyses were carried out by NATA accredited Queensland Health, Forensic \& Scientific Services, using flow injection colorimetric analysis (FIA) and inductively coupled plasma atomic emission spectroscopy, respectively. Bulk density was calculated gravimetrically from the difference in weight of a known volume of sediment before and after drying to a constant weight $\left(110^{\circ} \mathrm{C}\right)$.

Upper Brisbane River event mean concentration (EMC) was calculated from TSS samples derived from the event monitoring stations at Cressbrook and Gregor's Creek. EMC from Somerset Dam and Wivenhoe Dam outflows were calculated from turbidity profiles collected adjacent dam wall in each storage, using the YSI profilers as described above. Observed strong correlation between turbidity and TSS (see Fig. 7) allowed for conversion of turbidity measurements into TSS values for estimation of sediment inflows. Upper Brisbane River sediment input was calculated using sediment rating curves in Figure 8. Sediment rating curves were developed using linear models after log transformation of stream discharge and TSS concentration [13]. 


\section{Findings}

\subsection{Regional water storage sampling}

The extreme rainfall of January 2011 had variable impact on the TSS loading into the water storages, broadly grouping these into low impact and high impact systems. Low impact storages included the northern and southern region's Cooloolabin Dam, Baroon Pocket Dam, Leslie Harrison Dam, Hinze Dam and Little Nerang Dam. Highly impacted storages included central region's Wivenhoe Dam, Somerset Dam and North Pine Dam (Fig. 2), where TSS concentrations in these central storages where more than double compared to northern and southern storages (Fig. 2A). Further, the suspended solids in the central storages consisted of primarily inorganic sediments (75 to 90\%) in contrast to northern and southern storages that had corresponding values of less than $30 \%$ (Fig. 2B). Despite the relatively low organic matter composition in central storages, the greatly increased TSS values suggest significant organic loading was experienced with January 2011 inflows. All high impact storages were those with larger catchments and storage capacity, as well as relatively high catchment modification, and the reverse was true for low impact systems. (Table 1; Fig. 2).
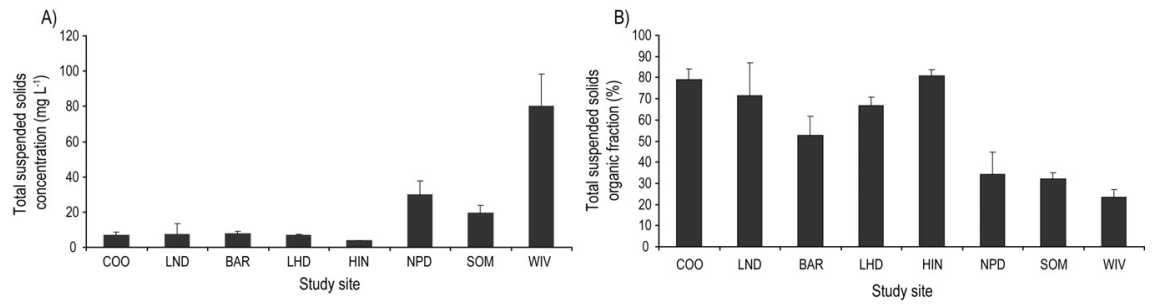

Figure 2: Initial survey (February 2011) of all water storages showing A) water column TSS concentration and B) organic content of the TSS. Values indicate average \pm standard error.

Long term average TSS concentrations adjacent extraction points, prior to the January 2011 inflow event, were similar between the low impact storage Hinze Dam (HIN $3.1 \pm 0.3 \mathrm{mg} \mathrm{L}^{-1}$ ) and high impact Wivenhoe Dam (WIV $3.2 \pm 0.1 \mathrm{mg}$ $\mathrm{L}^{-1}$ ) and North Pine Dam (NPD $4.6 \pm 0.2 \mathrm{mg} \mathrm{L}^{-1}$ ) (Seqwater monthly monitoring data, Brisbane). The high TSS values observed in the high impact storages (NPD and WIV), compared to low impact storage (HIN) after the inflow event, was reduced by an order of magnitude within the first month but only after a further 5 to 6 months did TSS levels return to that observed previously (Fig. 3). Rapid increases in TSS values immediately after the inflow event illustrate the importance of in situ sampling during inflow events to better quantify their impacts and develop sediment budgets. 


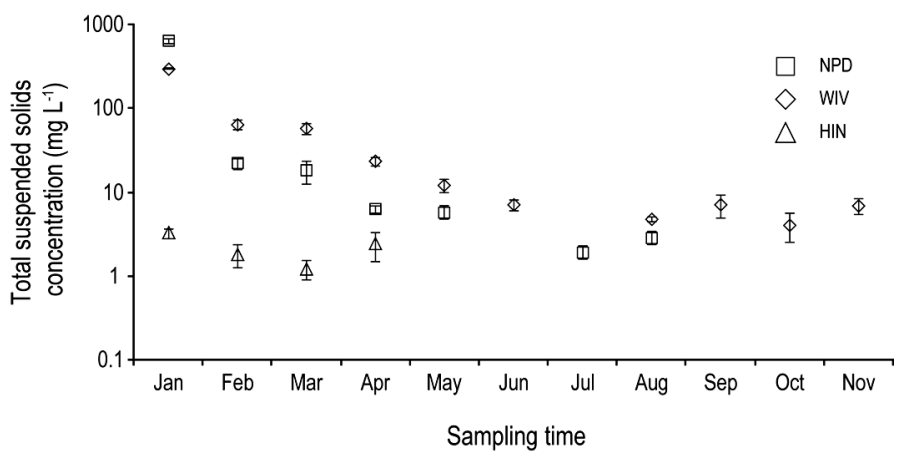

Figure 3: Post inflow total suspended solids concentrations in Hinze Dam HIN; Wivenhoe Dam (WIV) and North Pine Dam (NPD). Values indicate average \pm standard error from all sites and depths within each storage.

\subsection{Wivenhoe Dam case study}

In situ turbidity profiles revealed subsurface turbid inflows prior to peak January inflows and very high turbidity levels ( $>500 \mathrm{NTU}$ ) throughout the water column after peak inflow events (Fig. 4). Slow reduction in turbidity occurred over the ensuing months indicating settling of suspended particles. The Queensland water quality guidelines requires water storage turbidity levels to be less than $20 \mathrm{NTU}$ [14] and this condition was not met for a period of at least 6 months following inflows.

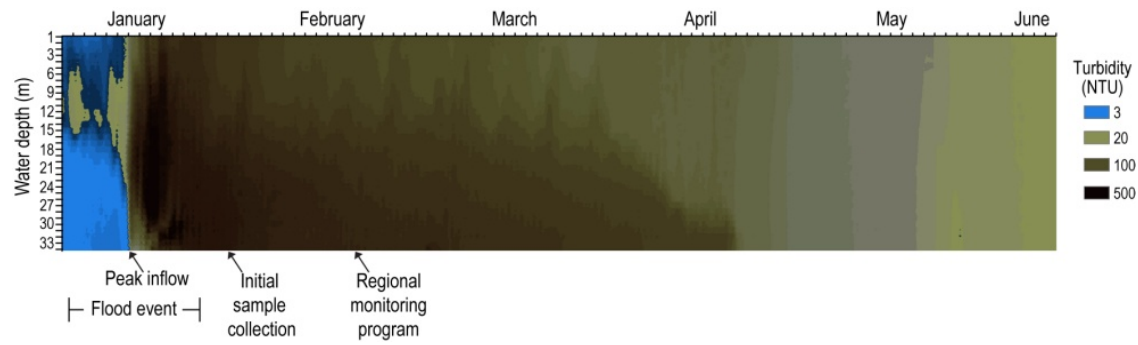

Figure 4: Turbidity profiling on Wivenhoe Dam Wall during and after the January 2011 flood event. Selected flow and sampling periods are highlighted.

The long term persistence of turbid conditions in Wivenhoe was likely due to the extremely small particle size of suspended particles. All sites in the dam had a median particle size less than $3.9 \mu \mathrm{m}$, the cut-off for clay particles, and the 10 percentile less than $1 \mu \mathrm{m}$ (the cut-off for colloids) (Fig. 5). Particle size distribution varied between sites across Wivenhoe Dam (Fig. 5) with waters adjacent inflow areas (Site 1, Fig. 5) containing relatively larger particles when compared to waters nearer the dam wall (e.g. Site 3, Fig. 5). 


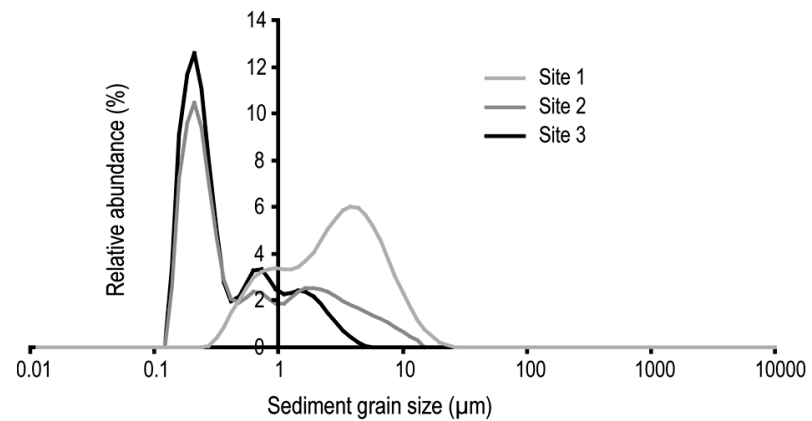

Figure 5: True particle size distribution of surface waters across Wivenhoe Dam in February 2011.

The site adjacent the dam wall (Site 3) that contained the relatively smaller particles in the water column, also had significantly higher manganese, nitrogen, phosphorus and sulphur sediment content compared with sites closer to the inflow (Site 1 and 2) (Fig. 6). Sediment aluminium and iron levels were at all sites approximately an order of magnitude higher than that of manganese (Fig. 6A). Sediment organic carbon concentrations were also an order of magnitude higher than that of nitrogen, which in turn, was approximately 3 times higher than that of phosphorus and sulphur (Fig. 6B). Surface sediment bulk density across all sites averaged $0.5 \pm 0.1 \mathrm{~g} \mathrm{~cm}^{-3}$ and ranged from 0.3 to $0.6 \mathrm{~g} \mathrm{~cm}^{-3}$.
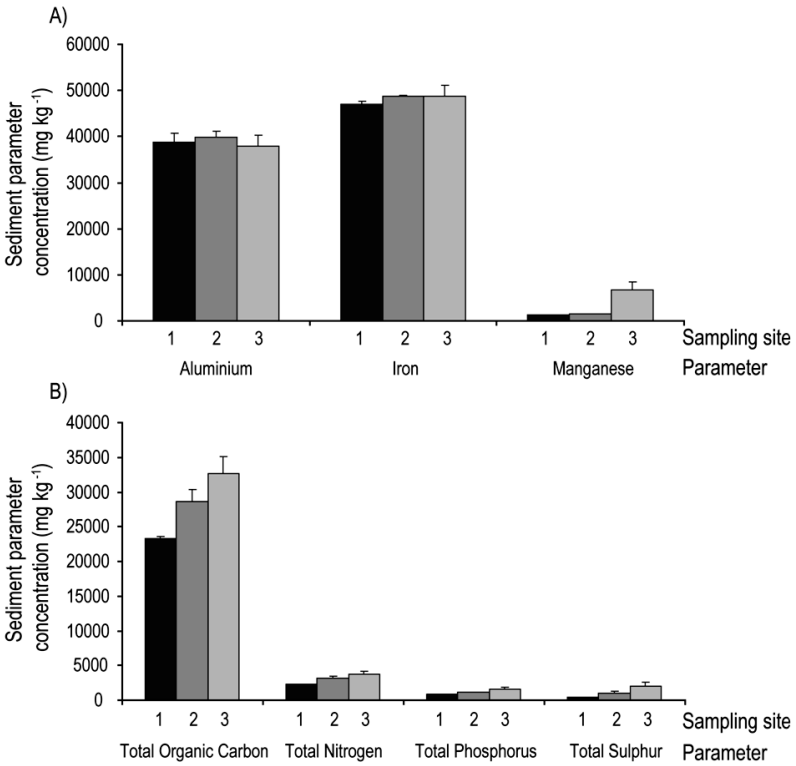

Figure 6: Surface sediment A) metal and B) nutrient concentrations in Wivenhoe Dam after the majority of particle settled post inflow event (April 2011). 
In order to estimate the sediment load delivered to the benthic zone of Wivenhoe Dam from settling of sediment solids, it is necessary to establish a robust relationship between TSS and turbidity. In this event, outflow TSS were not measured during the January flood event as access to Wivenhoe Dam Wall was not possible. Instead, turbidity profiles were continually monitored throughout the flood event. A strong, linear relationship between TSS and turbidity was obtained from post flood monitoring below Wivenhoe Dam Wall (Fig. 7), allowing detailed estimates of outflow suspended load.

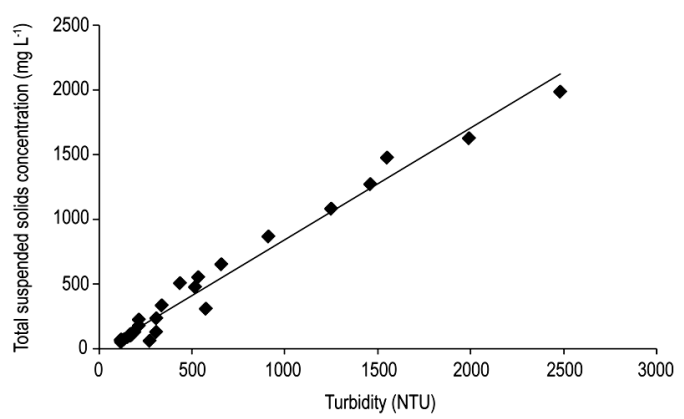

Figure 7: Relationship between TSS and turbidity below Wivenhoe Dam Wall collected in January-February 2011 (Linear regression y $=$ $\left.0.85 \mathrm{x} ; \mathrm{R}^{2}=0.98\right)$.

The total January 2011 inflow into Wivenhoe Dam was 2650000 ML between 2nd and 19th January 2011, 820000 ML from the Stanley River catchment and 1830000 ML from Upper Brisbane River catchment [5]. Outflow matched inflows over this time period as the dam level returned to preinflow levels and was assumed to be $2650000 \mathrm{ML}$. Assuming inflow TSS load from Upper Brisbane River of $1000 \pm 160 \mathrm{mg} \mathrm{L}^{-1}$ and Somerset Dam releases of $55 \pm 3 \mathrm{mg} \mathrm{L}^{-1}$ and average outflow $123 \pm 3 \mathrm{mg} \mathrm{L}^{-1}$, the sediment loading to Wivenhoe Dam can be estimated as $1557100 \pm 287310$ tonnes (Table 2).

Table 2: Estimated sediment loading from Upper Brisbane catchment and Somerset inflows during January 2011 flood event using the EMC method. Values represent average \pm SE [15].

\begin{tabular}{|c|c|c|c|c|}
\hline $\begin{array}{c}\text { Sediment } \\
\text { loading }\end{array}$ & Region & $\begin{array}{c}\text { Water volume } \\
\text { (ML) }\end{array}$ & $\begin{array}{c}\text { EMC TSS } \\
\text { (mg L-1) }\end{array}$ & $\begin{array}{c}\text { Total sediment } \\
\text { (tonnes) }\end{array}$ \\
\hline Inflows & Upper Brisbane & 1830000 & $1000 \pm 160$ & $1830000 \pm 292800$ \\
\hline & Somerset Dam & 820000 & $55 \pm 3$ & $45100 \pm 2460$ \\
\hline Outflows & Wivenhoe Dam & 2650000 & $123 \pm 3$ & $318000 \pm 7950$ \\
\hline Retained & & & & $1557100 \pm 287310$ \\
\hline
\end{tabular}

However, the EMC method using TSS samples collected from initial flows prior to peak flow are likely to greatly underestimate peak flow concentration. In addition, equal weighting was assigned to samples collected from Cressbrook 
Creek and Gregor's Creek, however, catchment condition and stream discharge differ greatly between the catchments and TSS loading will likely also differ between these systems as indicated in Figure 8.

An alternative method to estimate sediment retention within the Wivenhoe storage is through the use of measured storage inflows during the event coupled with sediment rating curves. This can be useful as suspended sediment sampling via event monitoring stations is limited, and these monitoring stations can be lost during extreme events, but stream discharge is generally monitored continuously. In the January 2011 flood, monitoring stations on the Upper Brisbane River collected stream discharge data for the duration of the event (Fig. 8A and B). TSS sample collection from Cressbrook Creek occurred on both rising and recession limbs as well as during inflow peak (Fig. 8A) whilst from Gregor's Creek sampling occurred only during initial inflow and no sample collection during peak inflow (Fig. 8B). Cressbrook Creek peak inflow was less than half that recorded from Gregor's Creek during the event. In addition, TSS concentration at Cressbrook Creek, even during peak inflow, was an order of magnitude lower than TSS concentrations recorded during initial inflow from Brisbane River at Gregor's Creek (Fig. 8A and B). These findings suggest Cressbrook Creek sediment loading were relatively small in comparison to Gregor's Creek loadings into Upper Brisbane River.

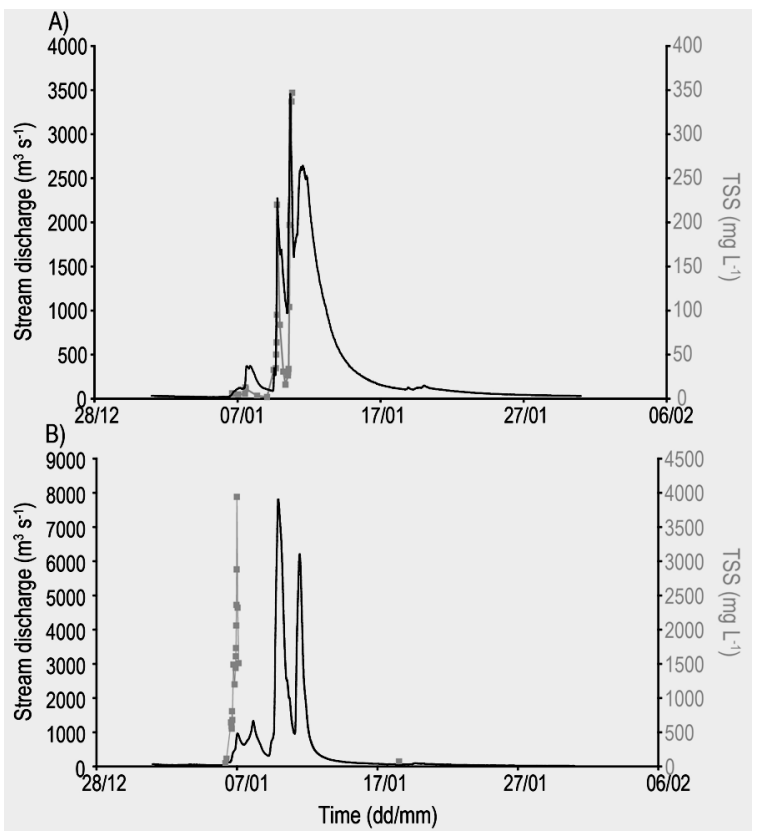

Figure 8: Stream discharge and total suspended solid (TSS) concentrations from A) Cressbrook Creek and B) Gregor's Creek over the January 2011 flood event [15]. 
Sediment rating curves were developed to better understand how these differences may impact sediment loading rates from Upper Brisbane River during the January 2011 flood event (Fig. 9A and B). The wide range of flow rates captured by the Cressbrook Creek sampling as well as samples on both rising and receding limbs (Fig. 8A) suggests this curve will predict sediment loading reasonably well (Fig. 9A). However, the rating curve developed for Gregor's Creek is based entirely on sampling from the rising limb of initial inflows without peak or recession limb sampling and provides a qualitative estimate at best (Fig. 9B).
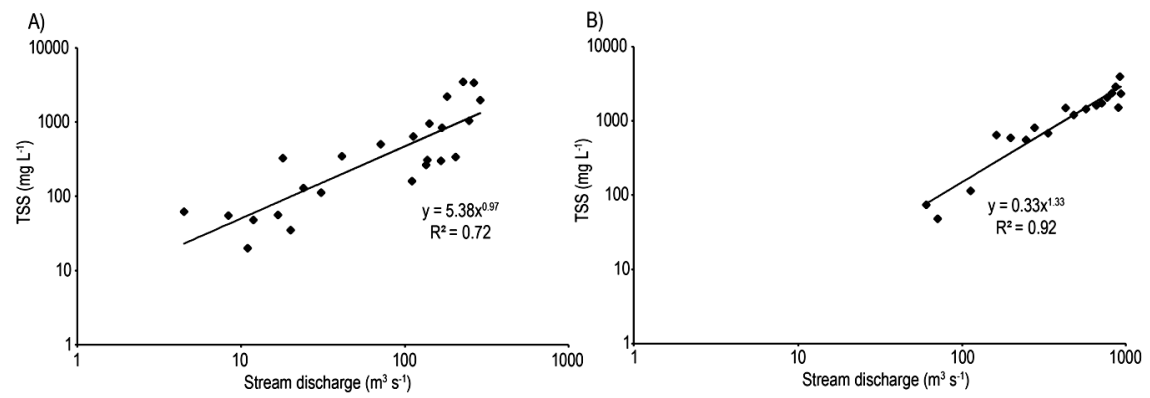

Figure 9: Sediment rating curves using total suspended solid (TSS) concentrations versus stream discharge and from A) Cressbrook Creek and B) Gregor's Creek over the January 2011 flood event [15].

Using the stream discharge time series data and sediment rating curves described above, a preliminary sediment loading budget was constructed (Table 3). These results further illustrates the importance of the sediment loading from Gregor's Creek to the Upper Brisbane catchment, as this appear to dominate the system with predicted sediment inflows 3 orders of magnitude larger than that of Cressbrook Creek (Table 3). An additional point of interest is the discrepancy between predicted Upper Brisbane inflows of $1830000 \mathrm{ML}$ (Table 2) and combined stream discharge from monitoring stations (Table 3)

Table 3: Estimated sediment loading from Upper Brisbane River catchment and Somerset Dam inflows during January 2011 flood event using rating curves method [15].

\begin{tabular}{|c|c|c|c|}
\hline $\begin{array}{c}\text { Sediment } \\
\text { loading }\end{array}$ & Region & Water volume (ML) & Total sediment (tonnes) \\
\hline Inflows & Gregor's Creek & 1076892 & 21197870 \\
\hline & Cressbrook Creek & 77947 & 56308 \\
\hline & Somerset Dam & 768690 & 44559 \\
\hline Outflows & Wivenhoe Dam & 2612765 & 319000 \\
\hline Retained & & -689235 & 20979328 \\
\hline
\end{tabular}


with over $600000 \mathrm{ML}$ unaccounted for. This suggests that lateral inflows directly into the water storage as well as runoff below the gauging stations represent important inputs of water (and sediment loading) into Wivenhoe Dam. Somerset Dam sediment inputs to Wivenhoe Dam were relatively low compared with the Upper Brisbane River, despite the large water volume released (Table 3). These suggest inflow waters into Somerset Dam contained lower sediment loading and/or sediment trapping within the storage itself further reduced suspended sediment concentrations of release waters.

The two methods used to estimate sediment input into Wivenhoe Dam during the January 2011 flood event provides a likely range of between 1500000 and 21000000 tonnes. Given the known sediment metal and nutrient composition, the likely range of total loading from these can also be calculated. Based on the two estimations of sediment loading and average nutrient/metal content across all sites, the total loading estimations into Wivenhoe Dam during the event were as follows: Aluminium 58266 to 815733 tonnes; Iron 72166 to 1010333 tonnes; Manganese 4733 to 66266 tonnes; Organic carbon 42333 to 592667 tonnes; Nitrogen 4600 to 64400 tonnes; Phosphorus 1817 to 25433 tonnes; Sulphur 1775 to 24850 tonnes. Even when only using the lower estimations of nitrogen and phosphorus input, these are 3 orders of magnitude higher than mean monthly loading for the Wivenhoe Dam system [16], resulting in this one event corresponding to over 80 years of mean loading rates. In addition, sediment bulk density may be used to estimate the loss of water storage capacity due to this inflow event and this loss is estimated to range from 3000 to $42000 \mathrm{ML}$. In total, such a loss represents 0.3 to $3.6 \%$ of the total storage capacity.

In conclusion, the January 2011 flood event resulted in massive sediment, nutrient and metal loading as well as loss of storage capacity in Wivenhoe Dam, the main water reservoir for the region. Events such as these are likely to increase in the future, calling for appropriate preparations and management decisions. The results presented here indicate that the water storage catchment (in terms of size, storage capacity and catchment modification) could be an important factor affecting the level of impact from extreme rainfall events.

\section{References}

[1] BOM, SOI (Southern Oscillation Index) Archives-1876 to present. Bureau of Meteorology: Melbourne, Online. http://www.bom.gov.au/climate, 2011.

[2] BOM, Frequent Heavy Rain Events in Late 2010/Early 2011 Lead to Widespread Flooding Across Eastern Australia; Special Climate Statement 24. National Climate Centre, Bureau of Meteorology: Melbourne, 2011.

[3] Chiew, F., and Prosser, I., 2011. Chapter 3: Water and climate. In: Prosser I (ed) Water: science and solutions for Australia. CSIRO Publishing, Collingwood, Victoria.

[4] van den Honert, R.C., and McAneney J., The 2011 Brisbane Floods: Causes, Impacts and Implications. Water, 3, pp. 1149-1173, 2011. 
[5] Seqwater, January 2011 Flood Event: Report on the Operation of Somerset Dam and Wivenhoe Dam. Flood Commission Report, Queensland Bulk Water Supply Authority: Brisbane, 2011.

[6] Beutel, M.W., Leonard, T.M., Dent, S.R., and Moore, B.C., Effects of aerobic and anaerobic conditions of $\mathrm{P}, \mathrm{N}, \mathrm{Fe}, \mathrm{Mn}$, and $\mathrm{Hg}$ accumulation in waters overlaying profundal sediments of an oligo-mesotrophic lake. Water Research, 42, pp. 1953-1962, 2008.

[7] Cai, W., and van Rensch, P., The 2011 southeast Queensland extreme summer rainfall: A confirmation of a negative Pacific Decadal Oscillation phase? Geophysical Research Letters, DOI: 10.1029/2011GL050820, 2012.

[8] Stimson, R.J., and Minnery, J., Why people move to the 'Sun-belt': A case study of long distance migration to the Gold Coast, Australia. Urban Studies, 35, pp. 193-214, 1998.

[9] OESR, Queensland Government population projections to 2031: local government areas, Office of Economic and Statistical Research, Brisbane, 2011.

[10] Moss, A.J., Bennet, J., Poplawski, W., Shaw, R., and Moller, G., Land use factors affecting the conditions of rivers, estuaries and bays in southern Queensland. Downstream Effects of Land Use, eds. H.M. Hunter, A.G. Eyles and G.E. Rayment, Department of Natural Resources: Brisbane, pp. 35-44, 1996.

[11] APHA, Standard methods for the examination of water and wastewater, 17th edition. American Public Health Association: Washington DC, 1998.

[12] Sperazza, M., Moore, J.N., and Hendrix, M.S., High-resolution particle size analysis of naturally occurring very fine-grained sediment through laser diffractometry. Journal of Sedimentary Research, 74(5), pp. 736-743, 2004.

[13] Crawford, C.G., Estimation of suspended-sediment rating curves and mean suspended-sediment loads. Journal of Hydrology, 129, pp. 331-348, 1991.

[14] DERM, Queensland Water Quality Guidelines, Version 3. Department of Environment and Resource Management: Brisbane, 2009.

[15] State of Queensland (Department of Environment and Resource Management), In consideration of the State permitting use of this data we acknowledge and agree that the State gives no warranty in relation to the data (including accuracy, reliability, completeness, currency or suitability) and accepts no liability (including without limitation, liability in negligence) for any loss, damage or costs (including consequential damage) relating to any use of the data. 2011.

[16] Burford, M.A., Green, S.A., Cook, A.J., Johnson, S.A., Kerr, J.G., and O'Brien, K.R., Sources and fate of nutrients in a subtropical reservoir. Aquatic Sciences, 74, pp. 179-190, 2012. 